International Journal of Cancer Studies \& Research (IJCR)

ISSN: $2167-9118$

\title{
Anticancer Activity of Acetone Extract of Quercus infectoria Olivier Fagaceae in 1,2 Dimethyl Hydrazine Induced Colon Cancer
}

Roshni P S ${ }^{1}$, Ramesh. K G ${ }^{2 *}$

Review Article

${ }^{1}$ Department of Pharmacology and Toxicology, Faculty of Pharmacy, Dharmsinh Desai University, Nadiad-387 001and Hemchandracharya North Gujarat University, Patan, India.

${ }^{2}$ Institute of Life sciences, Ahmedabad University, Ahmedabad-380 009, Gujarat, India.

Abstract
Quercus infectoria Olivier (Fagaceae) which contains abundant amount of hydrolysable tannins and traces of gallic acid, ellagic acid and sitos-
terol is reported to be effective in inflammatory bowel disease. In the present study, chemopreventive potential of acetone extract of $Q$.
infectoria (AEQI) $450 \mathrm{mg} / \mathrm{kg}$ was assessed in 1,2 -dimethylhydrazine (DMH) $(20 \mathrm{mg} / \mathrm{kg}$ ) induced colon cancer. DMH produced significant
development of aberrant crypts (AC) and aberrant crypt foci (ACF) associated with loss of body weight and high mortality. Treatment
of rats with AEQI not olnly prevented development of AC and ACF but also reduced mortality and loss of body weight. There was a
significant increase in oxidative stress (increase in MDA, MPO, NO and decrease in SOD) as well as TNF $\alpha$, TGF $\beta$ and VEGF. Treat-
ment with AEQI decreased not only oxidative stress but also oxidative stress and inflammatory factors. Our data suggest that $Q$. infectoria
possesses potential anti carcinogenic activity against colon cancer. Decrease in growth factors and anti oxidant activity may be responsible
for this anti carcinogenic effect.

Key Words: Quercus infectoria; TNF $\alpha$; TGF $\beta$; VEGF; Aberrant Crypt Foci.

\section{*Corresponding Author:}

Ramesh. K. Goyal

Distinguished Professor, Institute of Life sciences, Ahmedabad Univer-

sity, Ahmedabad-380 009, India.

E-mail: goyalrk@rediffmail.com

Received: March 09, 2013

Accepted: March 15, 2013

Published: March 18, 2013

Citation: Roshni P S, Ramesh. K G (2013) Anticancer Activity of Acetone Extract of Quercus Infectoria Olivier Fagaceae in 1,2 Dimethyl Hydrazine Induced Colon Cancer. Int J Cancer Stud Res. 2(1), 13-17. doi: http://dx.doi.org/10.19070/2167-9118-130002

Copyright: Ramesh. K G ${ }^{\circ}$ 2013. This is an open-access article distributed under the terms of the Creative Commons Attribution License, which permits unrestricted use, distribution and reproduction in any medium, provided the original author and source are credited.

\section{Introduction}

Adenoma of colon and rectum (colorectal cancer) is one of the commonly occurring cancers reported to cause 655,000 deaths worldwide. It is fourth most common form of cancer in United States and third leading cause of cancer-related deaths in the Western world (WHO 2006, NCI 2009). In India also the incidence of colon cancer is very large. During a 32-year period (1941-1972), 555 cases of colorectal cancer were recorded at the Tata Memorial Hospital, Mumbai[1]. In contrast a total of 560 cases of colorectal cancer were treated at the same institution in 2006 alone. Colon cancer as compared to rectal cancer occurs more frequently as a result of mutations in the signaling pathway that artificially increases signaling activity. The mutations can be inherited or acquired and occur in the intestinal crypt stem cell [2].
Aberrant crypt foci (ACF) are putative preneoplastic lesions of colonic neoplasia in rodents and humans. During the process of colon carcinogenesis, ACF appears in the early stages and subsequently develop into polyps, adenomas and eventually carcinomas [3]. Hence ACF development is commonly used as a parameter for assessment of colorectal cancer even in animals.

Current medical treatment in colon cancer consists of chemotherapy, hormonal treatment and targeted therapy. They are sophisticated, expensive and not widely available. Therefore, a search for novel anticancer agents from natural products may provide an alternative and cost-effective treatment modality [4]. The herbal drug Quercus infectoria is reputed plant in Ayurvedic system of medicine and commonly known as "Majuphul" in Ayurvedic literature. Tannins(gallotannic acid) is one of the main constituent found in the galls of Quercus infectoria in 50\%-70\%. Gallotannic acid a tannic acid is known for its anti-mutagenic, anticancer and antioxidant properties [5]. In present investigation we have studied the anticancer potential of $Q$. infectoria using 1,2-dimethylhydrazine induced colon cancer model in rats.

\section{Materials and Methods}

\section{Materials}

1,2-dimethylhydrazine (DMH) was purchased from Sigma Chemical Company. ELISA kit for TNF- alpha, TGF $\beta$ and VEGF from Nucleus inc. Ahmedabad. All other chemicals including solvents were of high purity analytical grade marketed by Dutt enterprise chemicals, Gujarat, India.

Identification, Collection and preparation of Acetone extract of Quercus infectoria 
Dried galls of Q.infectoria were obtained from a commercial supplier in Ahmedabad. It was authenticated by Dr. Hitesh A. Solanki, Reader Department of Botany, Gujarat University, Ahmedabad. Acetone extract of Q.infectoria was prepared. The yield of extract was $46.6 \%$. It was standardized by HPTLC taking gallotannic acid as marker.

\section{Induction of colon cancer}

Male albino Wistar rats weighing 150-200 gms obtained from Zydus research center Moraiya. Animals were cared for in compliance with the principles and guidelines of Council for the purpose of control and supervision of experimental animals (CPCSEA), ministry of environment and animal welfare, Govt. of India and approved by institutional animal ethical committee, in accordance with the Indian National Law on Animal Care and Use (Registration number: 1338/C/10/CPCSEA). The animals were housed 4 per polypropylene cage with a wire-mesh top and a hygenic bed of husk in a specific pathogen-free animal room under controlled conditions of a $12 \mathrm{~h}$ light/12 h dark cycle with temperature of $24 \pm 2{ }^{\circ} \mathrm{C}$ and relative humidity of $50 \pm 5 \%$ until the end of the experimental period. The rats were held in quarantine for 1 week and had access to food and tap water ad libitum. Commercial pellet diet containing $4.2 \%$ fat was powdered and mixed with $15.8 \%$ peanut oil, making a total of $20 \%$ fat. This modified diet was fed to all rats throughout the 16 week experimental period.

\section{Administration of carcinogen}

Colon cancer was induced by subcutaneous injections of $1,2 \mathrm{di}$ methylhydrazine (DMH) at $20 \mathrm{mg} / \mathrm{kg}$ once a week for the first 4 consecutive weeks. DMH was dissolved in $1 \mathrm{mM}$ EDTA; the $\mathrm{pH}$ was adjusted to 6.5 with $1 \mathrm{mM} \mathrm{NaOH}$.

\section{Treatment with acetone extract of $Q$. infectoria (AEQI) to ani- mals}

After 1 week of acclimatization, animals were randomly divided into six groups each containing ten rats.

Group I: Control

Group II: Rats treated with DMH $20 \mathrm{mg} / \mathrm{kg}$ sc weekly for four weeks.

Group III: Rats treated with DMH and AEQI $450 \mathrm{mg} / \mathrm{kg}$ p.o for 16 weeks.

Throught the period body weight of animals and mortality were recorded. At the end of sixteen weeks blood samples were collected and then rats were sacrificed.

\section{Assessment of anti cancer activity}

Animals were sacrificed by ether anesthesia at the end of fourth month from start of the experiment. The colons were removed, cleaned with saline solution $(0.9 \%)$ and slit open longitudinally from cecum to anus. Each colon was cut into proximal, middle and distal portion of equal length, and fixed flat between two pieces of filter paper in 10\% neutral-buffered formalin for at least $24 \mathrm{~h}$. Later, they were stained with 5\% methylene blue for 5 to $10 \mathrm{~min}$, and they were then placed on a microscopic slide; the mucosal side was observed through light microscope at 40x magnifications. ACF were counted by the method of Bird (1987) [6]. Crypts or distinct foci of crypts were counted as an ACF if they displayed at least two of the following characteristics [7]: (i) occupy a greater area than surrounding crypts; (ii) have a thickened epithelial lining; (iii) have elongated or altered shape of luminal opening; and (iv) have an increased pericryptal zone separating the crypt or foci from surrounding crypts.

\section{Estimation of Oxidative stress}

Part of colon isolated after 16 weeks were homogenized $(50 \mathrm{gm} / \mathrm{L})$ in $50 \mathrm{mM} / \mathrm{L}$ ice-cold potassium phosphate buffer $(\mathrm{pH}$ 6.0) containing $0.5 \%$ of hexadecyltrimethylammonium bromide. The homogenate was frozen and thawed thrice, then centrifuged at $4000 \mathrm{rpm}$ for $20 \mathrm{~min}$ at $4^{\circ} \mathrm{C}$. for the measurement of myeloperoxidase activity. Supernatant was collected and analyzed spectrophotometrically for malondialdehyde (MDA)[8], nitric oxide (NO) [9], myeloperoxidase (MPO)[10] and superoxide dismutase (SOD) [11].

\section{Detection of tissue vascular endothelial growth factor}

Yet another part of colon tissue was homogenized in $50 \mathrm{mM} / 1$ Tris buffer (pH 8.0) and centrifuged at 10000 RPM for $10 \mathrm{~min} .50$ $\mu \mathrm{L}$ supernatant were used for VEGF measurement. VEGF concentration were assayed by ELISA. Total protein was measured by Lowry's method[12].

\section{Detection of serum TNF $\alpha$ and TGF $\beta$}

At the end of 16 weeks before the animals were sacrificed blood samples were collected from retro-orbital plexus of the eye from $12 \mathrm{~h}$ fasted rats into vacutainer clotted tubes, where sera were separated by centrifugation within $30 \mathrm{~min}$ at $4000 \mathrm{rpm}$ at $4^{\circ} \mathrm{C}$ for 10 min using centrifuge, then divided into aliquots and kept at $-80^{\circ} \mathrm{C}$ for further assay of TNF-a and TGF $\beta$ immediately. Serum TNF- $\alpha$ and TGF $\beta$ were estimated by enzyme-linked immunosorbent assay (ELISA) [13].

\section{Statistical Analysis}

Results have been expressed as mean \pm standard error of the mean (SEM). Data were analyzed as a completely randomized design using One Way Analysis of Variance (ANOVA) followed by Dunnett's Post Hoc Test. The statistical significance was set at $\mathrm{P}$ $<0.05$.

\section{Result}

\section{Body weight and mortality}

Body weight of animals treated with DMH were found to be significantly reduced after 4 weeks and 16 weeks study period. There was also high mortality found in these animals. Treatment with AEQI significantly prevented not only the loss of body weight (Table 1) but also mortality in these animals (Table 1).

\section{Effect of AEQI on development of ACF induced by DMH}

There was development of colon ACF and AC in rats treated with DMH (Figure 1). AEQI treatment for 16 weeks significantly reduced the number of AC, ACF and crypt multiplicity as compared to DMH group (Table 2).

\section{Oxidative stress parameters}

Treatment with DMH produced significant increase in MDA, 
MPO, NO levels associated with significant decrease in colonic SOD as compared to control animals. Treatment with AEQI significantly prevented DMH induced increase in MDA, MPO and $\mathrm{NO}$ levels further it also produce increase in SOD levels (Figure 2).

\section{Serum TNF $\alpha$, TGF $\beta$ and tissue VEGF}

Serum TNF $\alpha$, TGF $\beta$ and tissue VEGF levels were increased with $\mathrm{DMH}$ administration to rats. This up regulation was prevented by treatment with AEQI. DMH caused elevation in TNF $\alpha$, TGF $\beta$ and tissue VEGF levels. Oxidative stress could be the additive factor which was induced by administration of DMH (Figure 3).

\section{Discussion}

In the present study rats treated with $\mathrm{DMH}$ were found to show presence of ACF and severity of dysplasia which indicates development of carcinomatous changes. Our findings are in consonance with those reported earlier.

ACF are indeed the earliest manifestations of colon cancer, and then ACF could provide insight into the earliest events of colon tumorogenesis.

The genesis of colon tumor is a multistep process, and ACF have been proposed to precede the earliest adenoma $[6,14,15]$.

DMH is used to produce Colon cancer, which is metabolized into the carcinogenic metabolite without previous metabolism by other tissues or colon bacteria in rat $[16,17]$. The ultimate carcinogenic metabolite of $\mathrm{DMH}$ is responsible for methylation of the DNA bases of various organs, including epithelial cells in the proliferative compartment of the crypts, which results in a great loss of colonic cells by apoptosis, an increase in proliferation, and an apparent increase in mutations of colonic epithelial cells[18]. All these alterations are likely to produce increase in inflammatory growth factors such as TNF $\alpha$, TGF $\beta$ and VEGF as well as oxidative stress. There was also an increase in mortality and decrease in body weight of the animals treated with $\mathrm{DMH}$, which may be due to induction of cancer by DMH.

Weight loss is an important prognostic factor in cancer; the higher the extent of weight loss, the shorter the survival time. The prognostic effect of weight loss is greatest in patients with a more favorable prognosis [19]. Treatment with AEQI reduces weight loss and DMH induced mortality in animals showed good prognosis in colon cancers.

Table 1. Effect Of Aeqi On Body Weight And Mortality Of Animals.

\begin{tabular}{|c|c|c|c|c|}
\hline \multirow{2}{*}{ Group/treatment } & \multirow{2}{*}{$\%$ mortality } & \multicolumn{3}{|c|}{ Body weight } \\
\cline { 3 - 5 } & & $\mathbf{1}^{\text {st }} \mathbf{w k}$ & $\mathbf{4}^{\text {th }} \mathbf{w k}$ & $\mathbf{1 6}^{\text {th }} \mathbf{w k}$ \\
\hline Group I & 0 & $248 \pm 7.5$ & $257 \pm 4.216$ & $250 \pm 3.416$ \\
\hline Group II(DMH) & $50 \mathrm{a}$ & $247 \pm 7.6$ & $222 \pm 7.92 \mathrm{a}$ & $168 \pm 3.651 \mathrm{a}$ \\
\hline Group III (DMH+ AEQI) & $10 \mathrm{~b}$ & $250 \pm 7.7$ & $238 \pm 6.541 \mathrm{~b}$ & $225 \pm 8.466 \mathrm{~b}$ \\
\hline
\end{tabular}

Each value is mean \pm SEM for 6 replicates in each group. ${ }^{a} P<0.05$ significant different from control and ${ }^{\mathrm{b}} P<0.05$ significant different from DMH treated control.

Table 2. Effect of Acetone extract of Q.infectoria on ACF formation in DMH treated rats.

\begin{tabular}{|c|c|c|c|c|}
\hline \multirow{2}{*}{ Group/treatment } & \multicolumn{4}{|c|}{ ACF formation in rat colon } \\
\cline { 2 - 5 } & Total AC & Total ACF & Crypt multiplicity AC/ACF & \% of ACF inhibition \\
\hline Group I & 0 & 0 & 0 & -- \\
\hline Group II(DMH) & $128 \pm 11.2$ & $47 \pm 5.1$ & $2.7 \pm 0.3$ & -- \\
\hline $\begin{array}{c}\text { Group III (DMH+ } \\
\text { AEQI) }\end{array}$ & $46 \pm 9.7 \mathrm{a}$ & $22 \pm 2.1 \mathrm{a}$ & $2.1 \pm 0.1 \mathrm{a}$ & \\
\hline
\end{tabular}

Figure 1. Histopathology of isolated rat colon staining with Hematoxylin and Eosine.
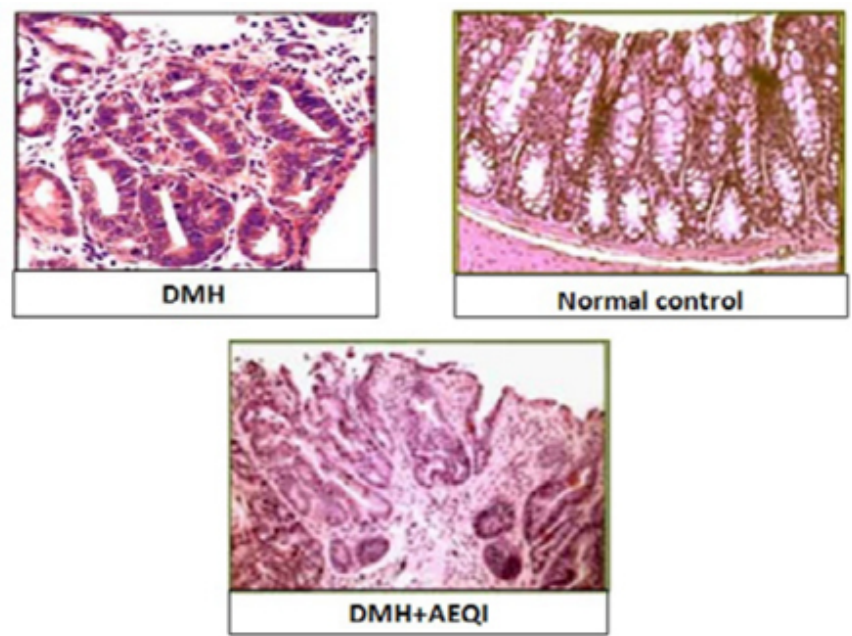
Figure 2: Effect of AEQI on MDA, MPO, NO and SOD.

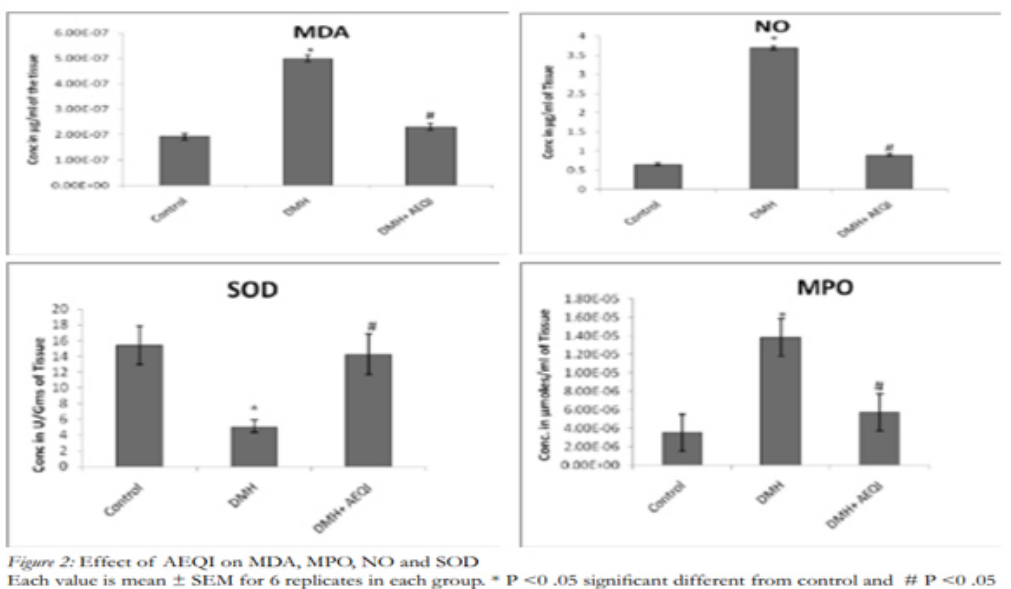

Each value is mean \pm SEM for 6 replicates in each group. ${ }^{*} P<0.05$ significant different from control and ${ }^{\#} P<0.05$ significant different from DMH treated control.

Figure 3: Effect of AEQI on VEGF, TNF $\alpha$ and TGF $\beta$ Level.

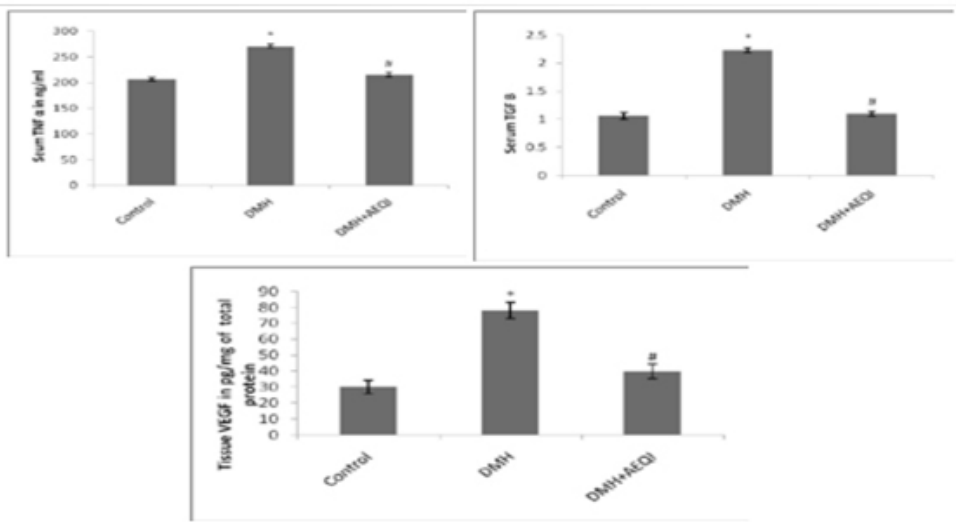

Each value is mean \pm SEM for 6 replicates in each group. $* \mathrm{P}<0.05$ significant different from control and \# $\mathrm{P}<0.05$ significant different from DMH treated control.

$\mathrm{ACF}$ and $\mathrm{AC}$ were found to significantly reduced in colon of rats treated with both $\mathrm{DMH}$ as well as AEQI, thus suggesting that AEQI possesses activity against DMH induced colon cancer. This is further strengthened by observation that there was significant reduction in mortality of rats treated with AEQI and significant prevention of the loss of body weight in rats treated with AEQI in addition to $\mathrm{DMH}$.

The phytochemical work carried by Umachigi et al., (2008) revealed that tannin is one of the active compounds which may be responsible for the antiproliferative activity [20]. Srivastava 2000 reported that gallotannic acid is antimutagenic in nature [5]. Several antioxidants in plants have been suggested to contribute to the anti carcinogenic effects and other such as flavanols have been able to inhibit cancer cell proliferation in vitro [21]. Inhibit ACF and $\mathrm{AC}$ generation by AEQI in colon may be due to presence of tannic acid.

Important to carcinogenesis, the unregulated or prolonged production of cellular oxidants has been linked to mutation (induced by oxidant-induced DNA damage), as well as modification of gene expression. In particular, signal transduction pathways, including AP-1 and NFxB, are known to be activated by reactive oxygen species, and they lead to the transcription of genes involved in cell growth regulatory pathways [22].
In addition to these many other chemical mediators are involved in carcinogenesis such as TNF- $\alpha$, which is an acute phase reactive protein which is responsible for many inflammatory diseases including caner of colorectal metastases confined to the liver [23] Further in colon cancers, loss of TGF- $\beta$ sensitivity is frequently accounted for by loss or mutation of known components of the TGF- $\beta$ signaling pathway, notably T $\beta$ RII and Smad4. Moreover VEGF expression was closely related with biological behavior of colon cancer and significantly associated with high intratumoral microvessel density (MVD) [24].

As mentioned above increased luminal activities of NO might be the aiding factor in tumor development. Taylor et al (1996) reported that iNOS gene expression is mediated by $\mathrm{NFKB}_{\mathrm{K}}$ [25]. Malondialdehyde is final product of oxidative stress and is good indicator for extent of oxidative stress [26]. Myeloperoxidase catalyses the conversion of proportionally more stable hydrogen peroxide to unstable hydrochlorus acid. This in turn promotes oxidative stress and additionally it induces neutrophil infiltration on mucosal area causing further damage to the tissue [27]. Preventive anti-oxidant, such as superoxide dismutase (SOD) enzyme is the first line of defense against reactive oxygen species [28]. Superoxide dismutase (SOD) is widely distributed in cells with high oxidative metabolism and has been proposed to protect such cells against the deleterious effect of superoxide anion[29].

In our studies we found anti oxidant and anti inflammatory po- 
tential of Q. infectoria. Kaur et al., (2003) showed anti oxidant and anti inflammatory potential of $Q$. infectoria which supports our finding [30]. Thus our data suggest that antioxidant effect of AEQI might be due to presence of tannic acid.

TNF is a member of a family of cytokines that are important for immune function and tissue homeostasis. Over expression of these ligands could contribute to tumor development by providing a defense that protects tumor cells by killing host immune cells. Similarly TGF $\beta$ induces angiogenesis and metastasis at late stage of tumor growth [31]. Guetz et al., 2006 said that overexpression of VEGF in colon cancer tissue indicated poor prognosis [24]. All these are important proinflammatory cytokines and their expression is under the transcriptional regulation $\mathrm{NF} x \mathrm{~B}$. In our studies we found that there was significant increase in TNF $\alpha$, TGF $\beta$ and VEGF. These fairly support the contention that TNF $\alpha$, TGF $\beta$ and VEGF are involved in colon cancer.

\section{Conclusion}

Data from our study suggest that $Q$. infectoria exerts a chemopreventive effect in $\mathrm{DMH}$-induced experimental carcinogenesis in rats indicating its potential as an anticancer drug for the treatment of colon cancer. The anticarcinogenic property of $Q$. infectoria in $\mathrm{DMH}$ induced colon carcinogenesis may be due to antioxidant property and reduction in the level of TNF $\alpha$, TGF $\beta$ and VEGF.

\section{References}

[1]. Jussawalla DJ, Gangadharan P (1977) Cancer of the colon: 32 years of experience in Bombay, India. J Surgical Oncology 9:607-22.

[2]. Ionov Y, Peinado MA, Malkhosyan S, Shibata D, Perucho M (1993) Ubiquitous somatic mutations in simple repeated sequences reveal a new mechanism for colonic carcinogenesis. Nature 363(6429): 558-61.

[3]. Sengottuvelan M, Senthilkumar R, Nalini N (2006) Modula-tory influence of dietary resveratrol during different phases of 1,2-di-methylhydrazine induced mucosal lipid-peroxidation, antioxidant status and aberrant crypt foci development in rat colon carcinogenesis. Biochim Biophysics Acta 1760:1175-1183.

[4]. Stevanovic A, Lee P, Wilcken N (2006) Metastatic breast can-cer. Australian Famacy Physician 35: 309-12.

[5]. Srivastava RC, Husain MM, Hasan SK, Athar M (2000) Cancer Letters 153: 1.

[6]. Bird RP (1987) Observation and quantification of aberrant crypts in the murine colon treated with a colon carcinogen: preliminary findings. Cancer Letters 37: 147-151.

[7]. Exon JH and South EH (2003) "Effects of sphingomyelin on aberrant colonic crypt foci development, colon crypt cell proliferation and immune function in an aging rat tumor model," Food and Chemical Toxicology 41:471-476.

[8]. Ohkawa I, Ohisi N, Yagi K (1979) Assay for lipid peroxides in animal tissue by thiobarbituric acid reaction. Annals of Biochemistry 95:351-358.

[9]. Lisa A ,Rindnour, Julia E, Micheal AH et al (2000) A Spectro-photometric method for the direct detection and quantification of nitric oxide, nitrates and nitrite in cell culture media. Analytical Biochemistry 281,223-229.
[10]. Chunxiang, Zhang, Lisa K et al. (2003) Interaction of my-eloperoxidase with NADPH oxidase derived reactive oxygen species in vasculature :implication for vascular defence. American Journal of Physiology, Circulation P physiology H2563-2572.

[11]. Misra HP, Fridovich I et al (1972) The role of superoxide ani-on in the autoxidation of epinephrine and a simple assay for superoxide dismutase. Journal of Biological Chemistry 1972; 247:3170 - 3175 .

[12]. Lowry OH, Rosenbrough NJ, Farr AL, Randall RJ (1951) Protein measurement with the Folin phenol reagent. Journal of Biological Chemistry 193: 265-275.

[13]. Bonavida B (1991) Immunomodulatory effect of tumor ne-crosis factor. Biotherapy 3:127-33.

[14]. Pretlow TP, Barrow BJ, Ashton WS, O’Riordan MA, Pretlow TG, Jurcisek JA. and Stellato TA (1991) Aberrant crypts: putative preneo-plastic foci in human colonic mucosa. Cancer Research 51: 1564-1567.

[15]. Roncucci L, Stamp D, Medline A, Cullen JB. Bruce W (1991) Identification and quantification of aberrant crypt foci and microadeno-mas in the human colon. Human. Pathololgy 22: 287-294.

[16]. Glauert HP, Bennink MR (1986) "Metabolism of 1,2- dimeth-ylhydrazine by cultured rat colon epithelial cells," Nutrition and Cancer 5(2):78-86.

[17]. Oravec CT, Jones CA, Huberman E (1986) "Activation of the colon carcinogen 1,2-dimethylhydrazine in a rat colon cell-mediated mu-tagenesis assay," Cancer Research 46(10): 5068-5071.

[18]. Chang WW (1984) "Histogenesis of colon cancer in experi-mental animals," Scandinavian Journal of Gastroenterology 19:27-43.

[19]. DeWys WD (1986) Weight loss and nutritional abnormalities in cancer patients: incidence, severity and significance. In: Clinics in On-cology, edited by Calman KC and Fearon KCH. London: Saunders 5(2): 251-261.

[20]. Umachigi SP, Jayaveera, KN, AshokKumar CK, Kumar G.S., Vrushabendra swamy BM \& KishoreKumar DV (2008) Studied on wound healing properties of Quercus infectoria. Tropical Journal of Pharmaceutical Research 7(1): 913-919.

[21]. Scalbet, A.,Johnson, I.T., \& Saltmarsh, M (2005) Antioxidants and beyond. American Journal of Clinical Nutrition 81: 215S-217S.

[22]. James E. Klaunig and Lisa M. Kamendulis (2004) The role of oxidative stress in carcinogenesis. Annual Review of Pharmacology and Toxicology 2004; 44: 239-267.

[23]. Kuppen PJ, Jonges LE, Van de Velde CJ, Vahrmeijer AL, Tol-lenaar RA, Borel Rinkes IH, Eggermont AM ( 1997) Liver and tumor tissue concentration of TNF- alpha in cancer patients treated with mel-phalan and liver perfusion Bristich Journal of Cancer 75(10): 1497-1500.

[24]. Des Guetz G, Uzzan B, Nicolas P, Cucherat M, Morere JF, Benamouzig R, Breau JL, Perret GY (2006) Microvessel density and VEGF expression are prognostic factors in colorectal cancer. Meta-anal-ysis of the literature. British Journal of Cancer 94:1823-1832.

[25]. Taylor BS, Shao L, Gambotto A, Ganster RW, Geller DA (1999) Inhibition of cytokine-induced nitric oxide synthase expression by gene transfer of adenoviral I kappa B alpha. Surgery 126:142-147.

[26]. Cheesman KH, Aruoma OI (1993) Lipid Peroxidation in Bio-logical Systems. In: DNA and Free Radicals. Ellis Horwood Publisher, London 12-17.

[27]. Sekizuka E, Grisham MB, Li MA, Deitch EA, Granger DN et al, (1988) Inflammation-induced intestinal hyperemia in the rat: role of neutrophils. Gastroenterology 95(6):1528-1534.

[28]. Halliwell B (1995) Antioxidant characterization: methodology and mechanism. Biochemical. Pharmacology 49, 1341-1348.

[29]. Fridovich I (1975) Superoxide dismutases. Annual Review of Biochemistry 44:147- 59 .

[30]. Gurpreet Kaur, Hinna Hamid, Asif Ali, Sarwar Alam M and Mohammad Athar (2004) Antiinflammatory evaluation of alcoholic extract of galls of Quercus infectoria Journal of Ethnopharmacology 90(2-3): 285- 292

[31]. Rebecca Elliott L and Gerard Blobe C (2005) Role of trans-forming growth factor beta in human cancer. Journal of Cclinical Ooncology Bbiology of Nneoplasia 23(9):2078-93. 